\title{
A study on the possibility of improving sulfide ore preparation characteristics using the pneumatic separation process
}

\author{
Sergey Zavialov, Yuri M orozov, and Roman Mamonov \\ U ral State M ining U niversity, 620144, 30, Kuibyshev st., Ekaterinburg, Russia
}

\begin{abstract}
The size, density of the particles and their shape play a significant role in the effectiveness of the pneumatic separation process. An experiment held using a lab machine revealed that the shape of the particles affects their warping from the air-flow. Research has shown that the airflow produced with the flat or narrow side of the ore which are flat and have a large form factor are more likely to be affected by the warping process. The impact of the ore shapes on the results of separating the pieces in terms of their density during the pneumatic separation process can be decreased by producing a structured feed-through into the air-flow using the flat side or by improving the previously selected ore pieces of a flat shape.
\end{abstract}

Traditional wet processes of enriching the ores using complex water slurry circuits are still presently sophisticated and expensive; they inevitably connected with the water consumption and its subsequent loss despite the high level of effectiveness of the separation process.

Dry enrichment processes could significantly simplify the ore treatment process and reduce the product cost in addition to solving a range of issues connected with storing and utilizing the waste products.

This paper provides the research results on the ore separation process at the Shatyrkul ore deposit using the dry gravitational methods.

The $X$-ray radiometric separation (XRS) is an efficient pre-enrichment method; XRS is used for ore classes which are $30 \mathrm{~mm}$ or larger in size. Depending on the part weight of the valuable component, the small classes of ores are either supplemented to the XRS concentrate or stored as separate refuse ore. In the first case scenario, there is a process of XRS concentrate dilution and in the second case scenario, the amount of valuable component extraction is decreased.

Incorporating small classes of ores into the treatment process without enriching them using XRS is an important contemporary and economically-beneficial trend aimed at improving the efficiency of ore pre-enrichment process.

The evaluation of the possibility for gravitational enrichment methods was performed by building the Henryk Czeczott Diagram [1] for the separated components. The calculations were made for the ore pieces of various density equivalent to $100 \mathrm{~kg} / \mathrm{m}^{3}$; this was done to identify the possibility of extracting fine tailings. 
Given these settings, the variation in the density between concentrate and the empty ore is equivalent to $100 \mathrm{~kg} / \mathrm{m}^{3}$. The formula proposed by N.F. Merinov [2] was used to calculate the free-falling velocity:

$$
v_{0}=\frac{24(\rho-\Delta) w}{d \cdot \Delta}\left(\sqrt{\mu^{2}+\frac{d^{3} w^{3} \Delta(\rho-\Delta) g}{216}}-\mu\right),
$$

where $d$ - particle size, m;

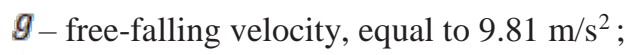

$\mu_{-}$dynamic viscosity coefficient, $1 \mathrm{~Pa}^{*} \mathrm{C}$;

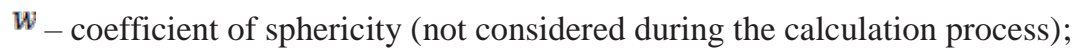

$\rho, \Delta_{-}$consequently, the particle and air density, $\mathrm{kg} / \mathrm{m}^{3}$.

The calculations were made for the class sizes ranging from 21 to $2 \mathrm{~mm}$. The ores with a class size smaller than $2 \mathrm{~mm}$ are further planned to be enriched using the flotation methods [3].

The collected data was used to build dependency diagrams of free-falling particles for the class sizes ranging from 21 to $2 \mathrm{~mm}$.

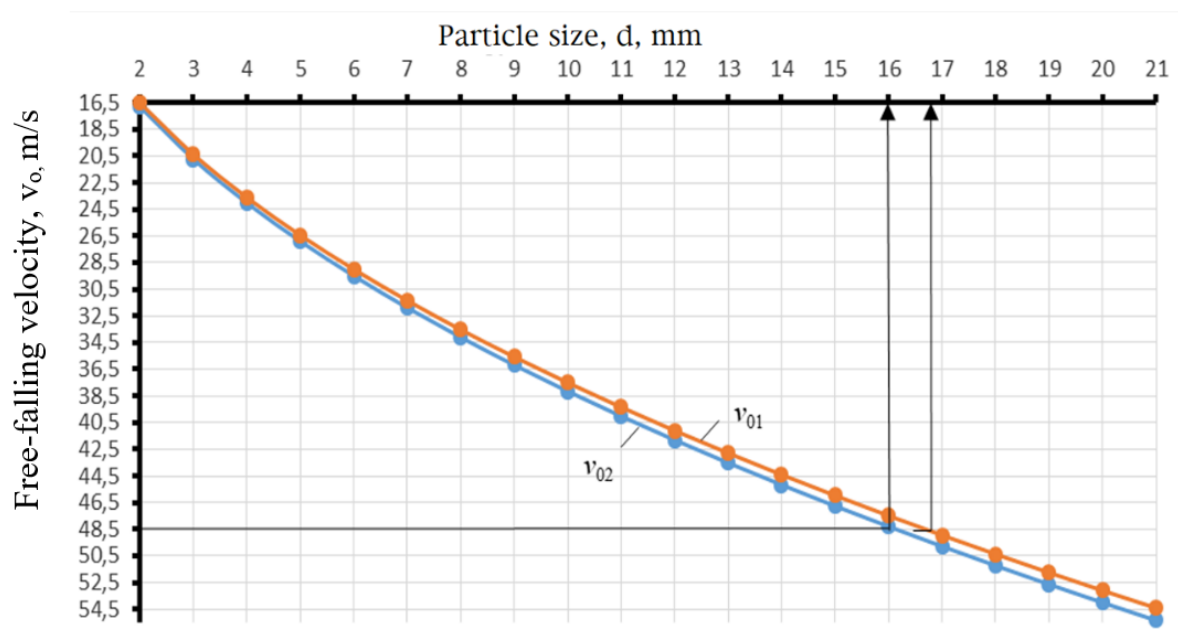

Fig. 1.1. Dependency diagrams of free-falling particles $v_{0}$ in relation to the diameter size of the particles $d$ ranging from 20 to $2 \mathrm{~mm}$.

The dependencies illustrated on Fig.1.1 help to identify which size classes the material must be subdivided into in order to achieve a successful selection in terms of their density with the implementation of dry gravitational enrichment methods. Based on this example, it can be seen that heavy-weight particles, $16 \mathrm{~mm}$ in size, will be selected depending on their density of the ore particles with content of waste copper reaching $16.9 \mathrm{~mm}$ in size [4].

The results show that it is necessary to implement a narrow classification of materials in order to complete the dry gravitational separation.

The ore properties were analyzed using the samples ranging in size from -20 to +18 $\mathrm{mm}$. Six ore samples of various shapes, mass and density were selected for the experiment.

The mass, volume, density and shape coefficient were defined for all the ore samples.

The length, width and height of each ore sample were used to calculate the shape coefficient (See Table 1) [5], [6]. 
In terms of its geometrical properties, the shape coefficient ( $K_{\phi}$ ) can be estimated using Formula 2 below.

$$
K_{\phi}=\frac{l}{b}+\frac{l}{h}
$$

where $l$ - ore sample length, $\mathrm{mm}$;

$b_{-}$ore sample width, $\mathrm{mm}$;

$h_{-}$ore sample height, $\mathrm{mm}$.

A $n$ example of calculating the shape coefficient $\left(K_{\phi}\right)$ of the first ore sample:

$$
K_{\phi}=\frac{l}{b}+\frac{l}{h}=\frac{3,4}{2,4}+\frac{3,4}{0,3}=12,75 .
$$

The shape coefficient $K_{\phi}$ calculation results in terms of the geometrical properties are given in Table 1.1.

Table 1.1. Ore samples properties

\begin{tabular}{|c|c|c|c|c|c|c|c|}
\hline $\begin{array}{c}\text { Sample } \\
\text { N o. }\end{array}$ & M ass, g & $\begin{array}{c}\text { Volume, } \\
\mathrm{cm}^{3}\end{array}$ & $\begin{array}{c}\text { Density, } \\
\mathrm{kg} / \mathrm{m}^{3}\end{array}$ & $\begin{array}{c}\text { Length, } \\
l, \mathrm{~cm}\end{array}$ & $\begin{array}{c}\text { Height, } \\
h, \mathrm{~cm}\end{array}$ & $\begin{array}{c}\text { Width, } \\
b, \mathrm{~cm}\end{array}$ & $\begin{array}{c}\text { Shape } \\
\text { coefficient }\end{array}$ \\
\hline 1 & 9,92 & 2,06 & 4815,53 & 3,4 & 0,3 & 2,4 & 12,75 \\
\hline 2 & 10,38 & 3,24 & 3203,7 & 3,3 & 0,5 & 2,1 & 8,17 \\
\hline 3 & 6,3 & 2,37 & 2658,23 & 2,9 & 0,4 & 2,5 & 8,41 \\
\hline 4 & 18,63 & 5,01 & 3718,56 & 3,2 & 1,3 & 1,5 & 4,59 \\
\hline 5 & 13,31 & 4,54 & 2931,72 & 2,8 & 1,4 & 2,9 & 2,97 \\
\hline 6 & 11,36 & 4,24 & 2679,25 & 3,6 & 1,3 & 2,1 & 4,48 \\
\hline
\end{tabular}

A laboratory machine was equipped to analyze the ore samples warping rates when incorporating the air-flow process. The concept scheme of the laboratory machine is presented in Fig. 1.2.

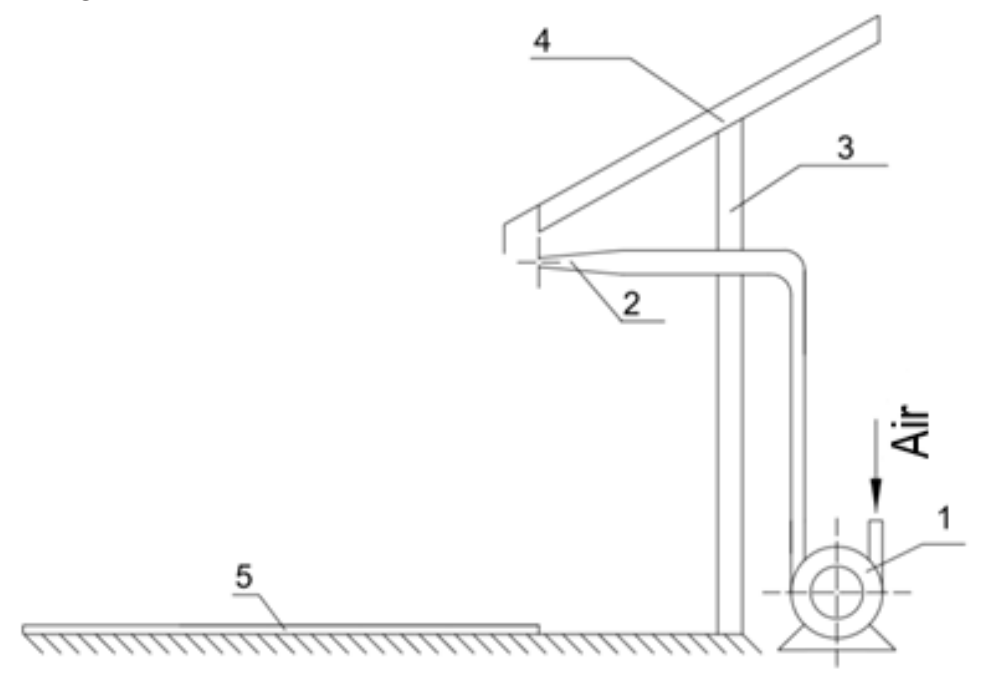

Fig. 1.2. A concept scheme of the laboratory machine designed for the study of ore samples warping: 1 -flotation mill; 2 - blowpipe; 3 - stoop; 4 - shovel trough; 5 -index bar 
The ore samples were placed on their flat side into the shovel trough 4; the ore samples were further sent automatically into the air-flow from the blowpipe 1 . The air-flow pressure from the blowpipe 2 reached $0.04 \mathrm{M} \mathrm{pa}$, the width of the blowpipe gapping was $2 \mathrm{~mm}$. The air-flow was aimed at a $90^{\circ}$ vertical angle. The blowpipe height distance to the measurement platform was $400 \mathrm{~mm}$ [7].

Each ore sample was passed through the air-flow a 100 times within the given experiment parameters. The distance from the initial point of the measurement platform axis to the ore free-falling point was measured using an index bar [8].

Figures 1.3-1.8 display the possibilities of separating the ore samples in terms of their length in various air-flow settings.
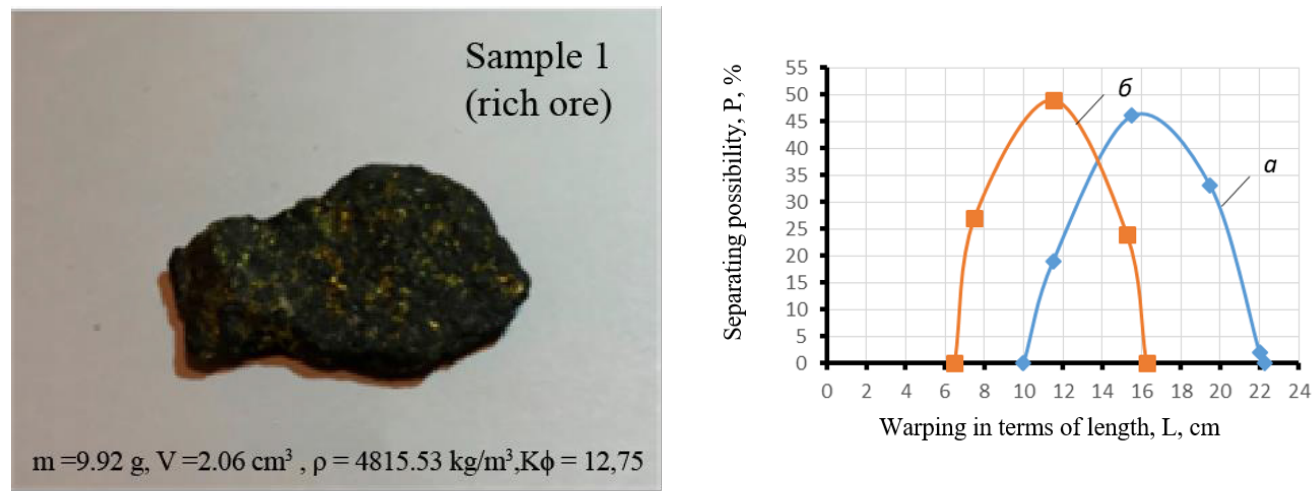

Fig. 1.3. The possible deviations in $P$ ore samples warping in terms of their length $L$ in conditions when the ore sample N 0.1 is placed into the air-flow with its flat side $(a)$ and narrow side $(b)$
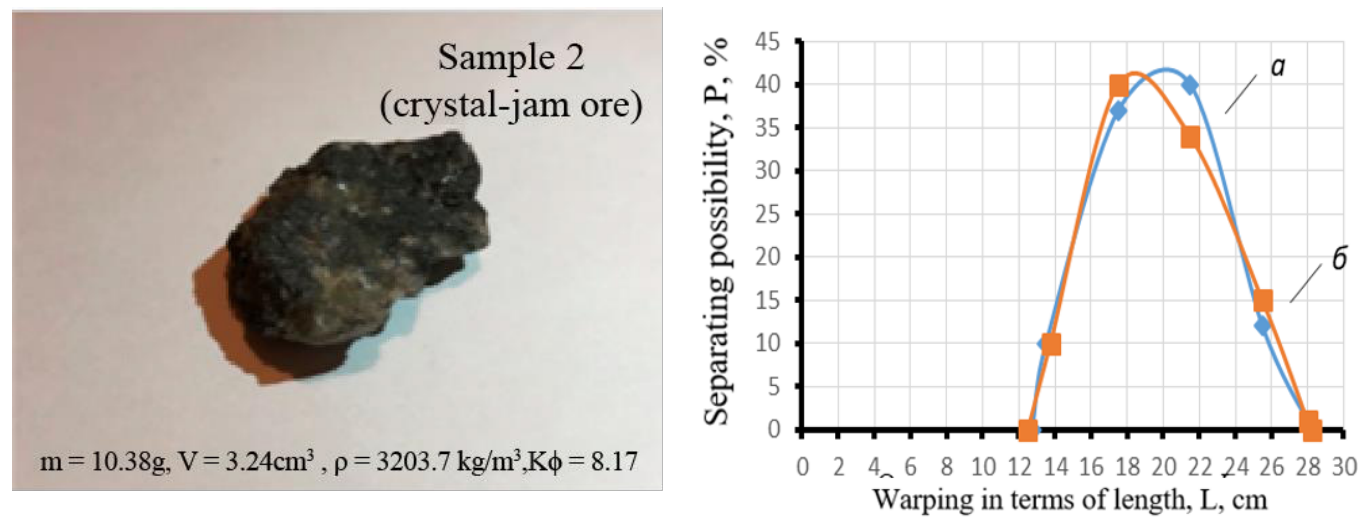

Fig.1.4. The possible deviations in $P$ ore samples warping in terms of their length $L$ in conditions when the ore sample N 0.2 is placed int 0 the air-flow with its flat side $(a)$ and narrow side $(b)$ 

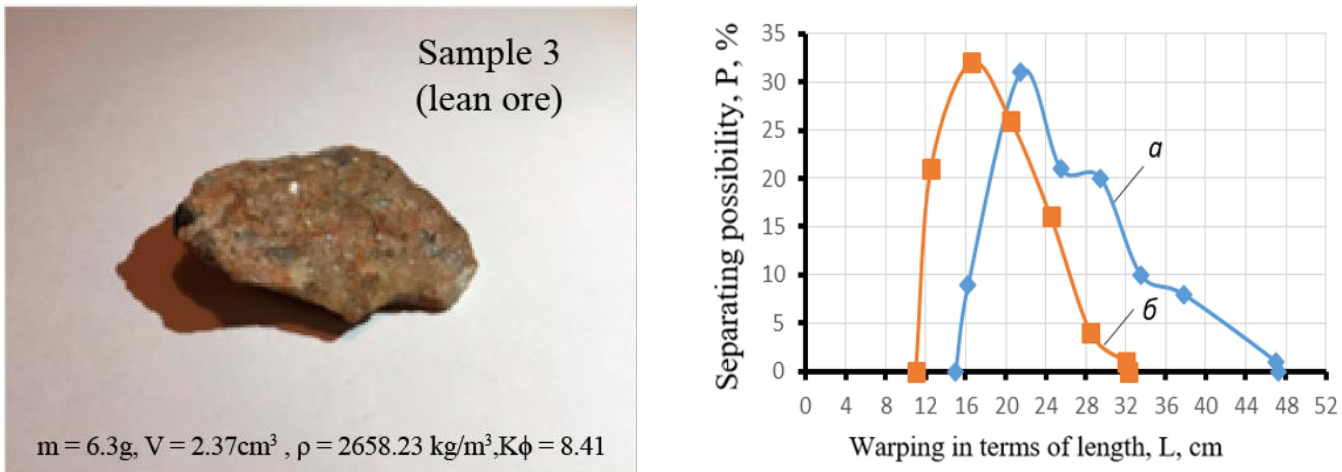

Fig. 1.5. The possible deviations in $P$ ore samples warping in terms of their length $L$ in conditions when the ore sample N 0.3 is placed into the air-flow with its flat side $(a)$ and narrow side $(b)$
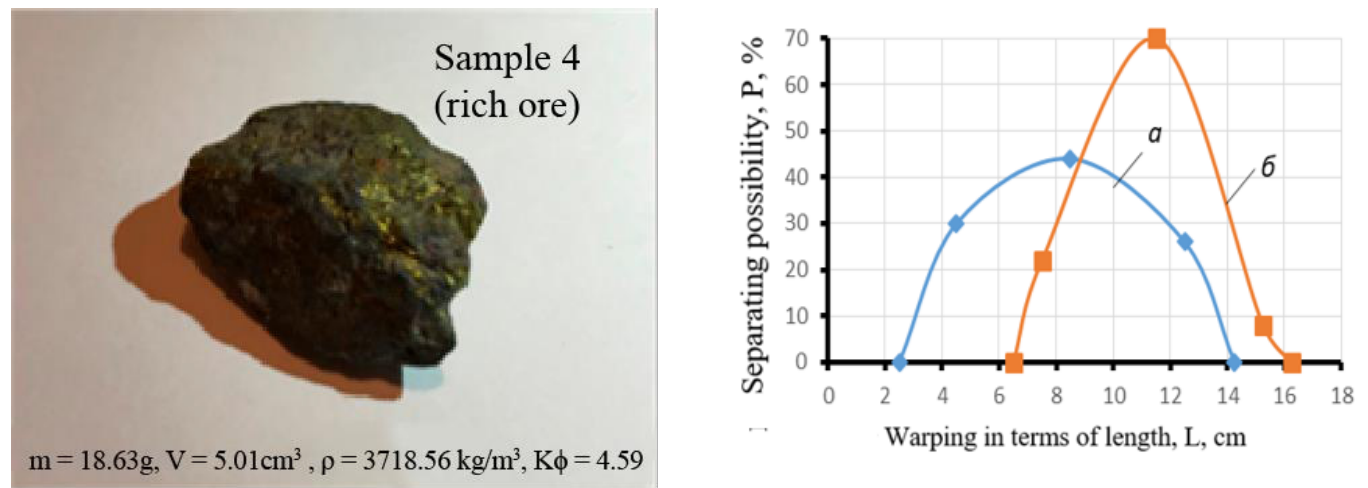

Fig. 1.6. The possible deviations in $P$ ore samples warping in terms of their length $L$ in conditions when the ore sample N 0.4 is placed into the air-flow with its flat side $(a)$ and narrow side $(b)$
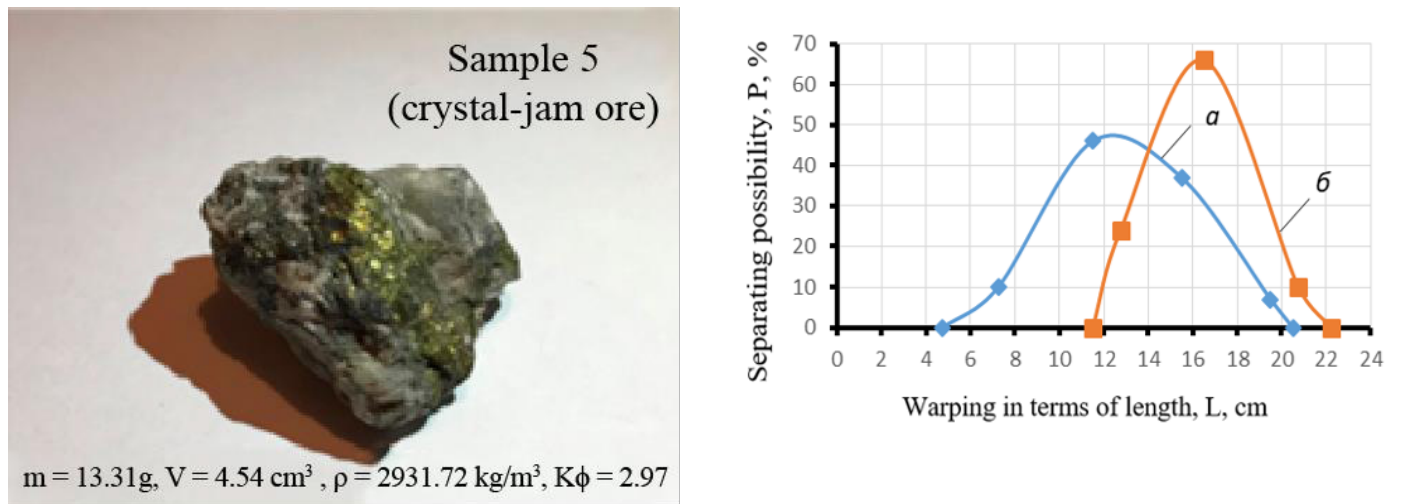

Fig. 1.7. The possible deviations in $P$ ore samples warping in terms of their length $L$ in conditions when the ore sample N 0.5 is placed into the air-flow with its flat side $(a)$ and narrow side $(b)$ 

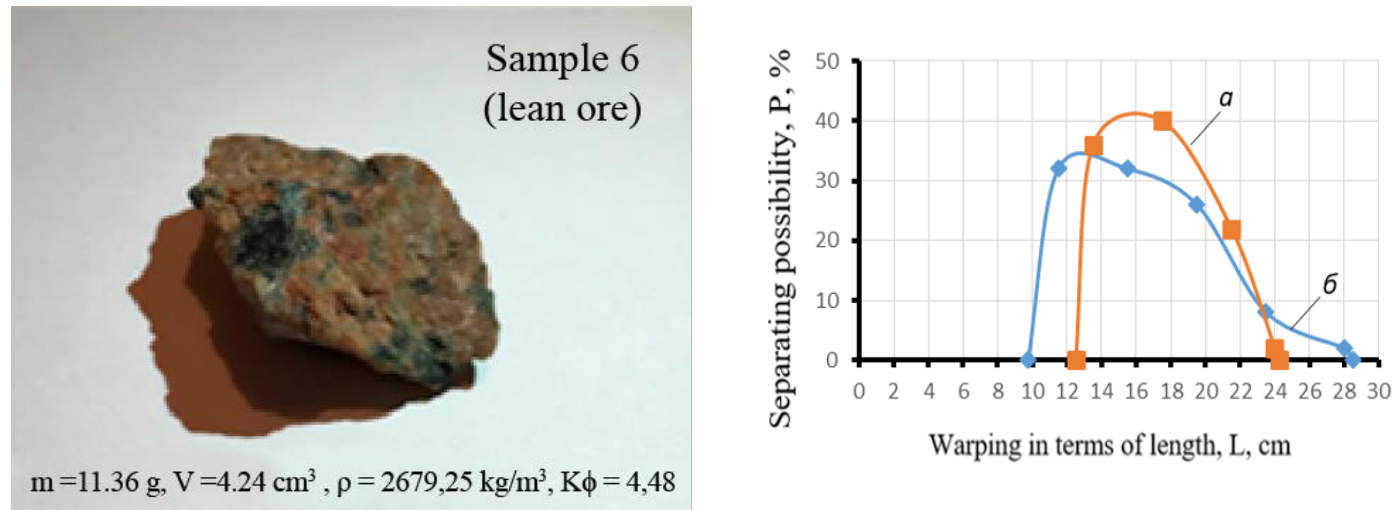

Fig.1.8. The possible deviations in $P$ ore samples warping in terms of their length $L$ in conditions when the ore sample N 0.6 is placed into the air-flow with its flat side $(a)$ and narrow side $(b)$

In general, the dependency analysis revealed that the lower the density of the ore samples, the more significant the influence of the ore shape on the particles warping range. Flat ore samples with a large shape coefficient are largely affected in terms of the warping by the air-flow with the samples sent into it with their flat or narrow side. Sending the ore sample with their flat side compared to sending them with their narrow side leads to a larger warping in their motion path. The impact caused by the ore samples shape on the separation results in terms of the ore sample density during the pneumatic separation process can be decreased by achieving a structured placement of the ore samples into the air-flow using their flat side. A nother trend is to hold a preliminary selection of the flat ore samples into a separate set which would be processed independently.

\section{References}

1. P.V. Lyashenko, Gravitational methods of ore processing, 264 (M oscow, 1935)

2. N.F. Merinov, Gravitational methods of ore processing. A short lecture course, 204 (Ekaterinburg, 2005)

3. T.I. Intogarova, O.S Valieva, Y u. P. Morozov, D.L. Tropnikov, A Mining Studies J ournal, 2, 48-51 (2019)

4. Y u.P. Morozov, S.S. Zavialov, H.R. Zhuraev, Innovative technologies of mineral and technological ore processing, 192-194 (Ekaterinburg, 2017)

5. Y u.P. M orozov, S.S. Zavialov, P.S. V olkov, H.R. Zhuraev, Research foundations and experience in ore and raw materials processing, 151-153 (Ekaterinburg, 2017)

6. S.S. Zavialov, M.S. Safonova, Research foundations and experience in ore and raw materials processing, 398-401 (Ekaterinburg, 2018)

7. S.S. Zavialov, M.S. Safonova, Research foundations and experience in ore and raw materials processing, 398-401 (Ekaterinburg, 2018)

8. E.F. Tsypin, Y u.P. Morozov, V.Z. Kozin, Modeling ore enriching processes and schemes, 368 (Ekaterinburg, U ral University Publishing, 1996) 